\title{
Can visual exposure impact on children's visual preferences for fruit and vegetables?
}

\author{
P. M. Heath ${ }^{1}$, C. Houston-Price ${ }^{1}$ and O. B. Kennedy ${ }^{2}$ \\ ${ }^{1}$ School of Psychology and Clinical Language Sciences and ${ }^{2}$ Department of Food and Nutritional Sciences, University of \\ Reading, Whiteknights, Reading RG6 6AL, UK
}

Evidence suggests that the consumption of fruit and vegetables $(\mathrm{F} \& \mathrm{~V})$ can reduce the risk of CVD and cancers of the mouth, lung and stomach. As dietary variety in infancy predicts continued healthy eating ${ }^{(1)}$, the early introduction and consumption of $\mathrm{F} \& \mathrm{~V}$ in young children is paramount to ensuring future public health. However, the introduction of new F\&V can be difficult, as between 8 and 15 taste exposures may be required in order for children to develop a taste preference for an unfamiliar food ${ }^{(2)}$. For children with high levels of food neophobia (a reluctance to try new foods), the introduction of $\mathrm{F} \& \mathrm{~V}$ into the diet can be even more challenging as high food neophobia is associated with lower levels of consumption of fruit and vegetables ${ }^{(3)}$.

Recent work by our group has demonstrated that visual exposure to pictures of unfamiliar fruits and vegetables impacts on both children's visual preferences for these foods ${ }^{(4)}$ and their willingness to taste them ${ }^{(5)}$. However, given that over-exposure of a liked food can lead to satiation or dislike ${ }^{(6)}$, it is possible that repeated visual exposure may similarly produce negative effects for foods that are already liked. To test this hypothesis, we explored how visual exposure affects visual preferences in infants showing high and low levels of food neophobia.

Sixty toddlers received a picture book about a fruit or vegetable that parents had told us was either liked, disliked or unfamiliar to the child. After 14 daily parent-administered presentations of the book, children's visual preferences towards exposed and non-exposed foods with the same initial status were measured using standard preferential looking techniques ${ }^{(4)}$. Neophobia was measured using the Child Food Neophobia Scale (CFNS) ${ }^{(7)}$. The table presents children's total looking times in milliseconds (ms) towards exposed and non-exposed foods.

\begin{tabular}{|c|c|c|c|c|c|c|c|c|c|c|}
\hline \multirow[b]{3}{*}{ Total looking time (ms) } & \multicolumn{4}{|c|}{ Liked foods } & \multicolumn{4}{|c|}{ Unfamiliar foods } & \multirow{2}{*}{\multicolumn{2}{|c|}{$\begin{array}{c}\text { Disliked foods } \\
\text { Vegetables }(n \text { 12) }\end{array}$}} \\
\hline & \multicolumn{2}{|c|}{ Fruit $(n$ 11) } & \multicolumn{2}{|c|}{ Vegetables $(n$ 12) } & \multicolumn{2}{|c|}{ Fruit $(n 12)$} & \multicolumn{2}{|c|}{ Vegetables $(n$ 12) } & & \\
\hline & Mean & $\overline{\mathrm{SD}}$ & Mean & SD & Mean & $\overline{\mathrm{SD}}$ & Mean & SD & Mean & SD \\
\hline$\overline{\text { Exposed }}$ & $3424^{\mathrm{a}}$ & 700 & 3016 & 481 & $3424^{\mathrm{a}}$ & 700 & $3683^{\mathrm{a}}$ & 526 & $3517^{\mathrm{a}}$ & 479 \\
\hline Non-exposed & 2361 & 446 & 2833 & 316 & 2361 & 446 & 2299 & 443 & 2652 & 460 \\
\hline
\end{tabular}

${ }^{\text {a }}$ Significant preference for exposed food, $P<0.05$.

For all categories, children looked longer at pictures of exposed foods than non-exposed foods. While this preference was not significant for liked vegetables, it is worth noting that there were no significant negative effects of exposure for any food group. There were also no significant differences in the behaviour of children with high and low levels of neophobia (all $P>0.05$ ). The robustness of the effect of visual exposure on children's willingness to look at foods suggests that this strategy should be explored as a means of increasing young children's intake of fruit and vegetables.

1. Cooke LJ, Wardle J \& Gibson EL (2004) Public Health Nutr 7, 295-302.

2. Sullivan SA \& Birch LL (1990) Dev Psychol 26, 546-551.

3. Cooke L, Carnell S \& Wardle J (2006) Int J Behav Nutr Phys Act 3, 14

4. Houston-Price C, Burton E, Hickson R et al. (2009) J Exp Child Psychol 104, 89-104.

5. Houston-Price C, Butler L \& Shiba P (2009) Appetite 53, 450-453.

6. Pliner P, Polivy J, Herman C P et al. (1980) Appetite 1, 203-213.

7. Pliner P (1994) Appetite 23, 147-163. 